\title{
Democracy, Environment and Security in Nigeria: Problematising the Environment in the Post-Military Era
}

\author{
Okechukwu Ibeanu \\ MacArthur Foundation, Abuja, Nigeria
}

\begin{abstract}
The Nigerian environment was adversely affected by prolonged military rule. Isolated internationally and pressured locally to democratize, successive military regimes intensified exploitation of natural resources, especially petroleum, to fund repression and corruption, thereby destroying the environment. Return to democratic government has raised hopes of redressing the environmental and social damages of military rule., though there remains skepticism about mainstreaming the environment in public policy. This paper discusses the link between environment protection, human security and democratic governance. It identifies two contending paradigms in the environment-security debate, namely the modernist-colonial and the traditional-organic, and argues that the continued dominance of the former, especially in the extractive industry, is conducive to environmental damage. Focusing on the Niger Delta, the paper advances four planks on which environmental restoration and human security could be achieved namely, assessment of vulnerabilities of people to environmental change/degradation, reform of institutional frameworks for dealing with vulnerabilities, community control of local resources and better environmental management and secure livelihoods.
\end{abstract}

\section{Introduction}

The environment was a major casualty of militmy rule in Nigeria. Pressured by popular demands to democratise and lacking in legitimacy, military regimes intensified exploitation of natural resources, especially petroleum, to fund repression and corruption. Petrodollars became a matter of survival for the military. This goal of regime security was perniciously portrayed as national security, notwithstanding that it contradicted the security of a vast majority of Nigerians by undermining the environment and livelihoods.

Inauguration of a democratic government in May 1999 raised hopes of redressing the ecological and social damages of military rule. Recently, the government in conjunction with bilateral and multilateral donors formulated a strategic plan for good governance in which the environment is expected to receive a major attention. Yet, among officials and academics 
there is still scepticism about mainstreaming the environment in public policy in the post-military era. Indeed, in many academic and policy circles the environment is not regarded as a priority for democratic governance. Environmental issues are seen either as the concerns of affluent Western societies, with little significance for the Third World, or a malicious diversion conjured by relevance-seeking international environmental NGOs. Either way, it is felt that "too much environmentalism" constitutes a fetter, rather than an impetus to Nigerian development. Thus, it has been suggested that to demand high environmental standards, especially in the petroleum industry, could deny government the resources necessary for socio-economic reconstruction and rehabilitation. This could lead to public disaffection and insecurity. The reasoning is Iftaipetrobusiness, being profit oriented, is likely to take its activities to other countries with less stringent environmental standards.

The reality, however, is that the environment is neither an issue for wealthy countries nor a phantom created by international NGOs. There are serious implications for developing countries like Nigeria. This is clearly so if we remember that 1.5 billion people in the world today live in poverty, 1.3 billion lack safe drinking water, 500 million are malnourished and another 25 million are environmental refugees. Surely, the bulk of these people are not in the United States, Germany or Japan. Instead, they live in countries like Nigeria. In fact, on the contrary, many policy makers in the developed world are not particularly supportive of global standards to save the environment. For instance. President George Bush has practically repudiated the Kyoto process, citing, among other things, its impact on the standard of living of Americans. What his position overlooks, however, is that only $4 \%$ of the world's population live in the United States. Yet, the United States generates $25 \%$ of all the world's greenhouse gasses, which in less than 25 years from now will lead to the submergence of Lagos and other coastal cities around the world in the ocean. The point is clear: our common future, both rich and poor countries, is inexorably tied to a clean environment and equitable distribution of resources within and between countries.

Is there then an environmental content to security and democratic governance in Nigeria today? If there is, how is it to be actualised in the aftermath of military dictatorship? These are the questions we seek to answer in this paper.

\section{Linking the Environment, Security and Democratic Governance}

Most people are wont to think of the environment purely as a natural category. However, while it may be true that nature exists irrespective of social, economic and political processes, it is also true that human perception of nature and how they construct and use the natural environ- 
ment are socially determined. Social construction of the environment involves values, expectations, structures and institutions that pattern human interaction with the biophysical environment. Behind each social construction of the environment always lie uncertainties, anxieties and conflicts for individuals, communities and states principally because they contain the ground rules for access and exclusion from resources. Excluded individuals, communities and states normally feel insecure. Consequently, the environment is crucial to a central issue of governance namely, the security of individuals and political aggregates like states. Yet, security is not exclusively a political issue, as is often suggested. It is also profoundly economic and social.

Security is paramount in human construction and use (abuse?) of the environment. Through most of history, recurrent issues in human claims to use of the environment are property rights of individuals and communities. These rights are economic, social and political in character. Thus, the state, the domain of politics, is the guarantor of particular systems of economic property and, through them, reproduces series of social relations and symbols that legitimise appropriation and exclusion. In all, the environment is intricately tied to social, economic and political processes that underline individual and collective security.

As Fig. 1 shows, this intricate unity is expressed in resource flows and regimes - access, exploitation and management. Political regimes and governance hold this linkage together. Insecurity is usually linked to faulty resource regimes. A faulty resource access regime is linked to exclusion from access of individuals and segments of the society, which not only heightens their sense of insecurity, but also becomes the basis for their mobilisation to overcome their exclusion. The end result is usually conflict and increased insecurity for both the included and excluded. Resource exploitation regimes produce insecurity linked to overexploitation of resources, depletion and degradation of the environment. This invariably reduces the carrying capacity of the environment and therefore heightens insecurity. Finally, faulty resource management regimes undermine long-term planning and are conducive to imbalances in the use of renewable and nonrenewable resources and poor environmental regulation regimes. In the process, sustainability of the environment and its long-term carrying capacity are jeopardised. It is only when the correct resource regimes are in place that the security of the state, communities and individuals is guaranteed in a socio-economic formation.

Experience would suggest that democratic governance, more than any other form of rule, is in a position to guarantee the balance between society, politics, economy and the environment necessary for establishing resource regimes that ensure security for the state, communities and the individual. This is because democracy demands that governments be accountable, consultative, representative and responsive. Nigeria's recent 
experience with military rule amply showed the negative impact of that form of rule on the environment and security, especially in the Niger Delta. The single most important manifestation of this was the politicisation of the environment, a situation in which local oil producing communities were pit-

Fig. 1: Interlocking Chains - Environment, Governance \& Security

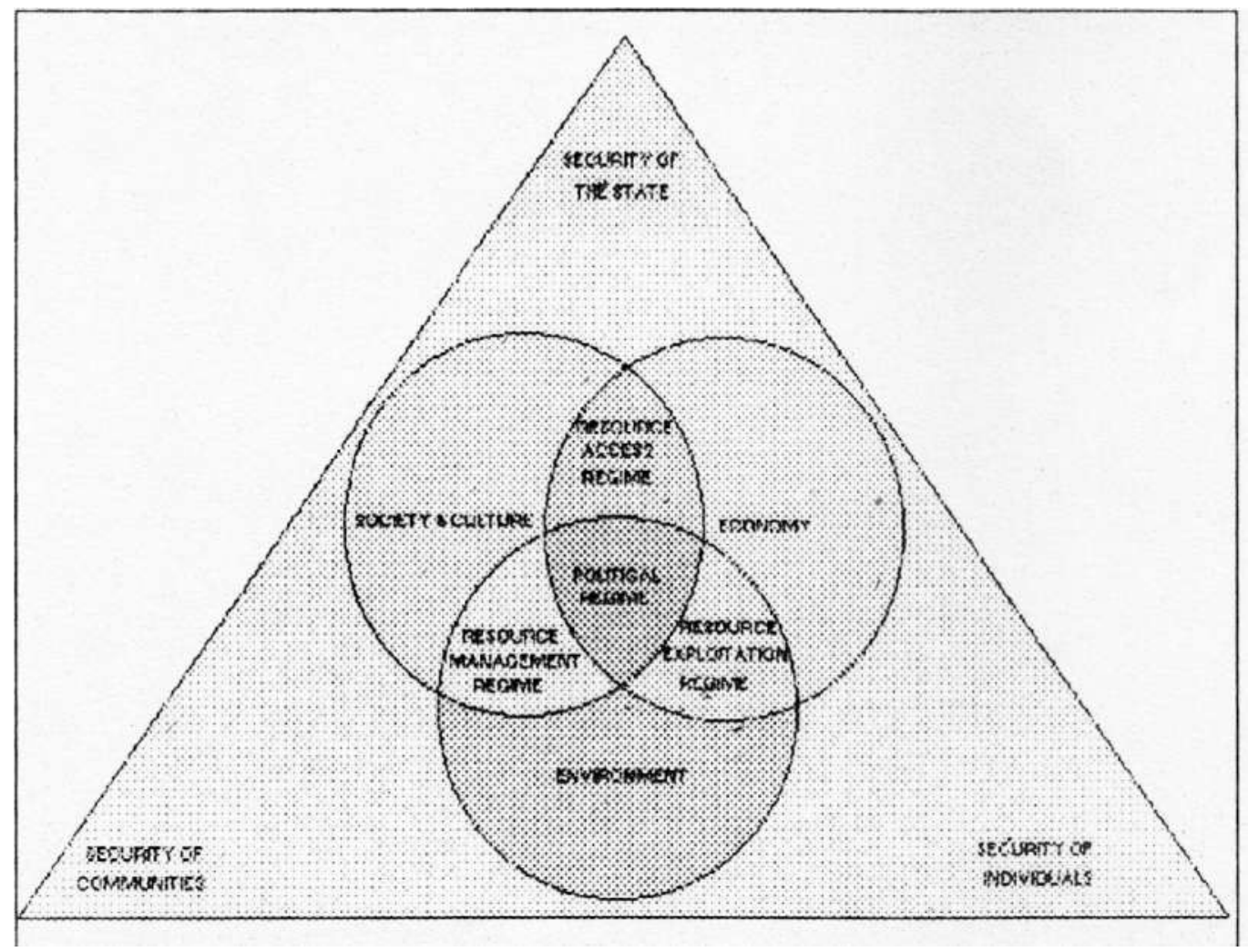

ted against state officials and petrobusiness like Shell Petroleum Development Company (SPDC). Clearly at issue in this environmental politics was security. For state officials and petrobusiness, state security took precedent over everything else, environmental security inclusive. Consequently, security meant an uninterrupted production of crude oil at "competitive" (read: low) prices in other to sustain state revenues. Informed by a pro-growth ideology, their concern is the production of petroleum to ensure economic growth (rents, royalties and profits). This is paramount irrespective of the impact on the local inhabitants and environment, or the economic irrationality of the process. For example, one of the paradoxes of oil exploitation in the Niger Delta is that renewable natural resources, such as arable land and aquifers, are destroyed for the extraction of a non-renewable, finite resource like crude oil.

On the part of local communities, security means the maintenance of the carrying capacity of the environment. It is a realisation that unsustainable exploitation of petroleum, with its devastation of farmland 
and fishing waters, threatens resource flows and livelihoods. Local people therefore demand guaranteed access to resources, including oil revenues. In addition, they demand the protection of the environment as part of guaranteeing that access and protecting their physical existence. For instance, the negative environmental impact of crude oil mining and refining is very well known. Pollution arising from oil spillage destroys marine life and crops, makes water unsuitable for fishing and renders farmland unusable. Brine from oilfields contaminates water formations and streams, making them unfit as sources of drinking water. At the same time, gas flaring in the vicinity of human dwellings and high pressure oil pipelines that form a mesh across farmlands are conducive to acid rains, deforestation and destruction of wildlife. In addition, dumping of toxic. nonbiodegradable by-products of oil refining is dangerous to both flora and fauna, including man. Metals that at high concentrations are known to cause metabolic malfunctions in human beings, such as cadmium, chromium, mercury and lead, are contained in refinery effluents constantly discharged into fresh water and farmland. They enter the food chain both by direct intake, for example through drinking water or indirectly through the consumption of seafood. Fish, for instance, is known to retain mercury in its brain without metabolising it, and man runs the risk of eating such contaminated fish.

These two perceptions of security, though contradictory, are not necessarily irreconcilable. The same issues are common in other parts of the world. But with the politicisation of the environment in the context of the rule of the military, consensus building is relegated in preference to regimentation through force and violence. State violence becomes the dominant means of addressing the contradiction between the state. petrobusiness and local communities. State violence expresses the violence and aggression of the state against targeted groups. This aggression occurs in the routine business of projecting power, carrying out policies without consultation or negotiation or spreading terror (Ake, et al, nd: 9). Often, state violence is used in support of the claims of one social group against those of others, rather than as part of the legitimate, institutional use of public coercion. State violence is a distinguishing feature of conflicts in the Niger Delta in the last decade because of the private appropriation of state power by various strata of the ruling elite, usually in the name of ethnic, religious, business and other sectional interests. As a result, the coercive apparatuses of the state, which should be above the specific interests of oil producing communities or petrobusiness, is employed brazenly to aggress, repress and suppress local communities.

Apart from the social, economic and political consequences of the rule of the military, which hinged on security, there were tremendous environmental consequences as well. State violence fuelled the inefficient exploitation of nature as groups that control the state use it to justify and 
perpetuate their unsustainable use of natural resources and degradation of the environment. For instance, oil companies with the backing of the state have engaged in some of the worst ecological practices in the world. Until recently, they did not conduct either environmental or social impact assessment before embarking on projects. Communities were seldom consulted. The oil companies often claimed that it was the responsibility of government to deal with the communities and that they satisfy all their statutory obligations. In the course of their activities, profound environmental damages, especially oil spills, were treated with the same levity. In 1970, about 30 million barrels of oil were spilled from Shell installations in Ogoniland. Between 1985 and 1993, there were 2,500 major and minor oil spills in Ogoniland, including a major one in which Shell dallied for forty days before patching a ruptured pipe (Earthaction, 1994). At Aleibiri in Ekeremor Council of Bayelsa State, a major oil spill on 18 March 1997 was left uncleaned by Shell for six months, prompting a demonstration by over 10,000 youths in August 1997 demanding an end to Shell activities in the Niger Delta. In January 1998, a massive oil spill from Mobil installations attracted over one million claims for compensation from individuals and communities. Out of these, Mobil accepted only 106,000 claims.

Apart from oil spills, there have been other environmental damages. For instance, Shell constructed a narrow road through the Ogoni town of Dere to link its oil wells. This completely destroyed the drainage system of the town, leading to sever flooding. To date, the community is still seeking compensation for thirty-nine years of suffering. In Gbaran, Shell also constructed a road to link its installations with a major road from Yenagoa to Mbiama. As a result, water flow to a large section of timberland was cut off and 1,000 acres of forest simply atrophied and died (Mitee, 1997: 6-9). In addition, gas flaring by major oil companies like Shell, Agip, Mobil and Elf is said to release 35 million tonnes of carbon dioxide and 12 million tonnes of methane into the atmosphere annually. In November 1983 alone, Shell flared over 483 million cubic metres of gas from its oil wells at temperatures up to $1,400^{\circ} \mathrm{C}$. Such tremendous ecological damage has led ethnic minorities in the Niger Delta such as the Ogoni, Ogba, Ijaw and Ikwerre to accuse petroleum companies of genocide.

Another important consequence of the rule of the military is that state violence makes environmental conflicts intractable and difficult to resolve. State violence leads to resistance by targeted groups, which leads to more violence and more resistance. For instance, in spite of heavy repression by the state, the Ogoni conflict went on for almost nine years. All activities of Shell have been grounded in the area for about seven years and there are yet no indications that they would resume. In Bayelsa State, the conflict between the state and Ijaw youths remains stalemated. Oil companies operating in the area continue to express fears for the safety of 
their staff. Among the oil producing communities, conflicts have become recurrent and endemic. The Ijaw and Itsekiri, Itsekiri and Urhobo, Ijaw and Ilaje, Kalahari and Nembe, Okpoma and Brass, among others, continue to simmer.

The problem is that the rule of the military made mediation, bargaining, negotiation, consensus- building and reciprocal concessions, which are desiderata for peaceful conflict management, very difficult. By substituting state violence for peaceful conflict management, the military created a situation of an unending cycle of conflict and violence in the Niger Delta. The inability of Nigeria's military controlled state to manage conflicts in the Niger Delta had to do with a general privatisation of the state. Rather than everybody's state standing above and balancing social antagonisms, the Nigerian state under the military was 'parcelled out' to various private and regional interests, particularly ethnic interests and petrobusiness. Consequently, the state was embroiled in conflicts, not as an arbiter, but as an active party canvassing the interests of some groups against others. In effect, the state became essentially a repertory of violence used against specific groups, instead of a repository of all the interests of the people-nation. The Ijaw and Ogoni were two groups in the Niger Delta repeatedly targeted by privatised state violence. I have explored their horrid experiences elsewhere (Ibeanu, $1999 ; 2000)$. Suffice it to say, however, that a commentary on the struggles of the peoples of the Delta that petrobusiness and the Nigerian state are now popularising is that the Niger Delta, especially the Ogoni and Ijaw are inherently, perhaps naturally, aggressive. This reminds one of the stereotypes of colonial anthropology. Unfortunately, this line is gaining grounds in academic (read: pseudo-academic) circles. However, what is not said is that for half a century petrobusiness and the state violently repressed these peoples. Yet, apart from muted forms of organised resistance in the 1960s, the peoples of the Niger Delta did not respond to their repression until the 1990s, making their equanimity unparalleled in history.

\section{Colonial Origins of Environmental Insecurity}

Environment-security discourses have become very widespread in research and policy literature since the end of the Cold War (Homer-Dixon, 1991; Baechler, 1998; Hyden, 1999). This is not surprising because in the post-Cold War period the environment has emerged as a major global challenge commonly facing the security community. These discourses reflect dominant social constructions of the environment and security. The underlying epistemological differences among them are profound. Yet, these differences are scarcely addressed in the literature. In this regard, we can identify two principal epistemological traditions to wit, the modernist-positivist and the traditionalistorganic. The former, which came to Africa 
through colonialism, constructs the environment as something external to be exploited for present needs. These needs are essentially defined by big business. It is principally economy-driven and supports intensive exploitation of nature. It is also oriented towards the market for the purpose of short-term profitability and supports individual ownership of resources and knowledge. By contrast, the traditionalist perspective constructs the environment in synergy with socio-cultural realities of people as something to be carefully managed for the present and future. It is human-centred and emphasises organic use of resources for sustainable livelihoods based on community ownership of resources and knowledge. Unfortunately, it is the colonial tradition that continues to predominate in Nigeria.

The origins of the misconceptions of the Nigerian environment and consequent environmental mismanagement, therefore, lie largely in colonialism. Specifically, they lie in the colonial state's project, which consisted of keeping down a conquered but restive people, extracting resources and repatriating surplus to the colonial metropolis. To accomplish this project, environmental management and sustainable use of resources were subordinated to the central concern of accumulation, defined as economic growth. In this circumstance, what security meant to the coloniser and what it meant for the colonised were fundamentally different. For the coloniser, economy was separate from and precedent to ecology. The coloniser, therefore, constructed the environment as extraneous, to be exploited for capital accumulation, notwithstanding damning social and biophysical consequences. For the colonised, on the other hand, the new capitalist economy of the coloniser undermined the unity of social existence with the natural environment. It, therefore, threatened culture, distorted livelihoods and destroyed the environment.

These two social constructions of the environment cohere with two different perceptions of security. The positivist/modernist/colonial construction of security focuses on state/regime (national) security. It is based on a vertical, exclusive and competitive view of power, and it lays emphasis on military power, threats and threat containment. By contrast, traditionalist/organic construction of security focuses on human security and welfare. State security makes sense only to the extent that it serves human development and secures livelihoods. The traditionalist/organic perspective on security informs the worldview of local communities in Nigeria. Consequently, in many parts of the country, local people are currently challenging the colonial construction of the environment-security nexus, as propagated by big business and government officials, because fails to secure equitable resource flows environmental protection and, therefore, livelihoods. 


\section{Strategic Issues in Environment and Good Governance in Nigeria}

In the aftermath of military rule, there are serious concerns about Nigeria's natural resources, soil quality, erosions/floods, water management, sustainable energy and desertification. This is particularly so in the Niger Delta where nearly half a century of oil exploration has devastated the environment. A starting point in tackling these issues is to reconcile the different approaches to environment and security that exist between state officials, big business and local communities. One approach to reconciling these contradictions is the concept of human security, which aims at harmonising environmental, physical and economic security and survival for the state, communities and individuals. As the UNDP notes, human security is an "integrative" as opposed to merely a "defensive" concept Human security transcends the realist, pro-growth approach of big business and state officials, which subordinates the environment and local livelihoods to the demands of accumulation and state security. It also transcends ecofetishism, which idealises the environment.

On the basis of discussions of human security (Lonergan et aL, 2000), there are three steps for a strategy to integrate environmental issues and democratic governance. First is the assessment of socio-environmental vulnerabilities of communities and provision of options for overcoming them. This assessment must address questions such as why are certain groups more vulnerable to environmental change than others? What coping strategies are available to what groups? Why do some groups cope better than others do? What type of intervention measures by the state is necessary to improve the capacity of people to overcome socio-environmental vulnerabilities?

Second is to increase the capacity and freedom of people to exercise the options necessary for them to overcome socio-environmental vulnerabilities. This must address issues such as striking the right balance between the role of the public and private sectors, as well as communities in resource use and management. This calls for the establishment of the right institutional framework for socio-environmental management. Finally, the third step involves the activation of popular participation in implementing these options.

Based on the foregoing, a plan of action for integrating environmental issues into democratic governance in Nigeria in the short to medium term should focus on the following (Table 1):

- Assessing vulnerabilities of people to environmental change/ degradation in the major geographic and ecological zones of the country, especially the Niger Delta;

- Developing and/or updating institutional frameworks for dealing with these vulnerabilities; these should focus on conflict resolution 
mechanisms, international agreements, domestic legislation and specialised agencies like Environmental Protection Agencies at local, state and federal levels; and Community participation in resource control and environmental monitoring and protection; this call for training, publicity and capacity building.

Table 1: Summary of Proposed Actions for Actualizing the Strategic Plan

\section{Strategic Issues}

1. Assess vulnerability of people to environmental change and degradation in the major geographic and ecological zones of Nigeria

2. Develop and/or update institutional frameworks for dealing with socioenvironmental vulnerability

3. Support community participation in resource control, environmental monitoring and protection

\section{Proposed Actions}

Commissioned participatory research, surveys, workshops and publications Support for the Ministry of Environment to establish independent and efficient regulatory processes Accede to major international environmental Conventions and Protocols Legislation by National Assembly, State Assemblies and Local Councils in compliance with major international environmental Conventions and Protocols Formulate, update and implement national resource use policies, with an emphasis on food security, water, waste/pollution, disaster and coastal zone management, pristine sites, biodiversity, land-use and landcover, energy and industrial transformation Establish proactive environmental conflict management structures, linking the three tiers of government, civil society organisations and local communities 
- Establish community-based resource management regimes

- Develop guidelines on corporate community relations for major corporations, especially in the petroleum and mining industries, to cover community participation, re-investment and affirmative actions

- Local training, publicity and capacity building in the area of environmental monitoring and protection

\section{Implications for the Niger Delta}

What do the foregoing mean for the Niger Delta? In a recent assessment of the social conditions for democratic consolidation in the Niger Delta, we found that six issues stood out (IDEA, 2000: 249). They were:

(a) desirability of democracy;

(b) restructuring and resource control;

(c) alleviation of poverty and improvement of infrastructure;

(d) gender equity;

(e) intra-Delta conflict management; and

(f) environmental remediation and protection.

The assessment adopted a participatory methodology that emphasised the genuine possession of the process by the peoples of the Niger Delta. Insofar as that process was followed, the people shaped the issues that emerged. The desirability of democracy expresses a deep-seated feeling among people in the Niger Delta that military rule was inextricably linked to the poor social and environmental conditions of the region. At the same time, it also means that remediation and restitution are only possible with an end to military rule and return to democracy. However, they make a clear distinction between democracy and civilian rule. Repeatedly, what we heard in the Delta was that civil rule is just the beginning of the journey to democracy. The teleological end of this journey must be to redress the socio-environmental problems of the Niger Delta. The path to this consists of three sets of concerns namely, institution building and popular participation, both underscored by a process of vulnerability assessment 
participation, both underscored by a process of vulnerability assessment (Fig. 2). The first involves building institutions that ensure environmental remediation and protection, as well as effective management of conflicts in the Niger Delta. The second is popular participation, which calls for the democratic restructuring of the Nigerian state and making resource control more just and equitable. Equity should address questions of gender discrimination, the profound poverty that blights the people of the region and the terrible state of physical infrastructure. We also think that what ties all these together is a constant evaluation and re-evaluation of socio-environmental vulnerabilities in the Niger Delta. This calls for an integrated process of participator\}' research and advocacy work. The gains accruing from the end to military rule must not be taken for granted. They have to be protected and deepened.

Fig. 2: Some Interactions of Democracy and the Environment

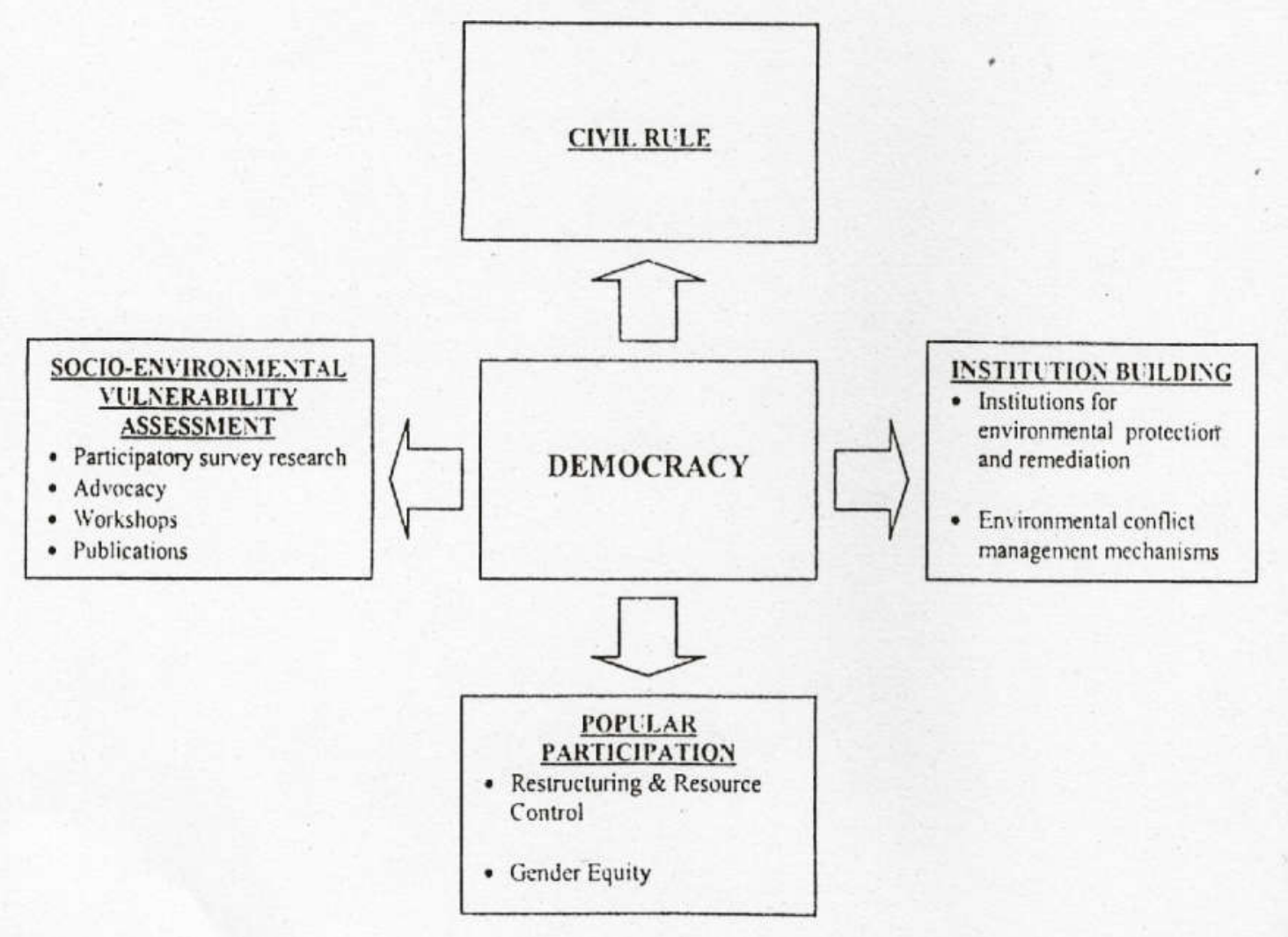




\section{Conclusion}

The aims of this reflection on environment and governance in a post-military Nigeria are essentially to raise issues and point directions. We have argued the link between democratic government, human security and the environment in Nigeria, showing that military rule was conducive to widening and deepening socio-environmental vulnerabilities of Nigerians, especially in the Niger Delta. This happened in three dominant ways. First, the military's unsustainable exploitation of petroleum undermined livelihoods, destroyed the environment and increased the vulnerability of people, especially the poor. Second, the inability of successive military regimes to use the billions of petrodollars the country earned from crude oil exports to transform the country economically and socially due to corruption and poor policy choices, drastically reduced the choices available to Nigerians and undermined capacity to adapt to worsening environmental situations. Finally, the inability of the military to institute effective institutional mechanisms for environmental monitoring and remediation meant that vulnerabilities deepened, threatened communities became restive, while the state became exceedingly repressive.

From the foregoing, there are three strategic issues facing the new democratic government in the area of the environment. These three interwoven strategic issues are vulnerability assessment, increasing the choices available to people to overcome these vulnerabilities and increased capacity" of people to make these choices. It is only when these three conditions are realised that human security can be guaranteed. Unfortunately, the new government has been slow in instituting the necessary institutional framework for better environmental management and a workable road map to achieving human security, especially in the oil producing areas of the country. Instead, its preoccupation with maintaining the flow of oil money together with a tendency to be beholden to petrobusiness and international financial institutions assured that the first term of the administration was one of missed opportunities.

\section{References}

Ake, C. et al (not dated) 'The Causes of Conflict in Africa', Port Harcourt: Centre for Advanced Social Science.

Baechler, G. (1998) 'Why Environmental Transformation Causes Violence:

A Synthesis', Environmental Change and Security Project Report,

Issue 4 (Spring), Washington D.C.: The Woodrow Wilson International

Centre for Scholars

Homer-Dixon, T. (1991) 'On the Threshold: Environmental Changes as

Causes of Acute Conflict', International Security 16(2). 
Hyc.'n, G (1999) 'Environmental Awareness, Conflict Genesis and Governance', in Granfelt, T. (ed), Managing the Globalised Environment: Local Strategies to Secure Livelihoods, London: Intermediate Technologies Publication.

Ibeanu, O. (1999) 'Ogoni - Oil, Resource Flow and Conflict in Rural Nigeria', in Granfelt, T. (ed), Managing the Globalised Environment: Local Strategies to Secure Livelihoods, London: Intermediate Technologies Publication.

Ibeanu, O. (2000) 'Oiling the Friction: Environmental Conflict Management in the Niger Delta, Nigeria', Environmental Change and Security Project Report, Issue 6 (Summer), Washington D.C.: The Woodrow Wilson International Centre for Scholars.

International IDEA (2000) Democracy in Nigeria: Continuing Dialogue(s) for Nation Building, Stockholm: International IDEA.

Lonergan, S., Gustavson, K., and Carter, B. 2000. The Index of Human Insecurity', AVISO: Information Bulletin on Global Environmental Change and Human Security, Issue No. 6 (January).

Mitee, B. (1997) "The Social-Cultural Impact of Oil Exploration on an Indigenous People: The Ogoni Case' (Paper presented at the international symposium on Economic, Social and Cultural Rights among the Sami, the Maasai and the Ogoni, University of Lapland, Rovaniemi, Finland, 12-14 September). 